\title{
Reconstruction of fingers after electrical injury using lateral tarsal artery flap
}

\author{
This article was published in the following Dove Press journal: \\ Therapeutics and Clinical Risk Management \\ 10 July 2017 \\ Number of times this article has been viewed
}

\author{
Minghua Zhang \\ Mitao Huang \\ Pihong Zhang \\ Pengfei Liang \\ Licheng Ren \\ Jizhang Zeng \\ Jie Zhou \\ Xiong Liu \\ Tinghong Xie \\ Xiaoyuan Huang \\ Department of Burns Reconstruction \\ Surgery, Xiangya Hospital, Central \\ South University, Changsha, Hunan, \\ People's Republic of China
}

\begin{abstract}
Objective: Electrical injuries to the fingers account for the majority of total severe burns that occur each year. While several types of flaps have been used in covering finger defects, all have limitations or disadvantages. The purpose of this study was to introduce our clinical experiences of using the lateral tarsal artery (LTA) flap to successfully restore fingers after electrical injury.

Patients and methods: From 2005 to 2012, 10 patients with 14 severe electrical burns to their fingers, including six thumbs and four index and four middle fingers, were treated with LTA flap. The wound size ranged from $2.0 \times 3.0 \mathrm{~cm}$ to $3.5 \times 5.0 \mathrm{~cm}$. The flap with free tendon graft was used to repair the tendon defect in four cases, free nerve graft was used to repair the feeling defect in two cases, and the flap with nerve was used to repair the feeling defect in two cases. All the patients were followed up for 3 months to 2 years.

Results: All skin flaps adhered successfully and there were no complications. All patients were satisfied with the esthetic appearance and functional outcome of the finger reconstruction.

Conclusion: LTA flap is a reliable method to restore fingers after severe electrical injuries.

Keywords: electrical injuries to fingers, lateral tarsal artery flap
\end{abstract}

\section{Introduction}

Burn injuries to hands and upper extremities account for $>70 \%$ of total severe burns. More than $58 \%$ of these cases are the burns to both hands. The courses of trauma to hands are variable, including flame, scald, and electrical, chemical, and physical contacts. In the case of electrical burns, several factors determine the injury severity, including amperage, resistance of the body at the point of contact, type and magnitude of current, current pathway, and the duration of the current flow.

The greatest resistance is conferred by the bone tissue, followed, in descending order, by the tendons, adipose tissue, skin (depending on humidity), muscle tissue, blood vessels, and nerve tissues. Increasing resistance of these tissues increases the extent of disability. Electrical injuries can also cause immediate death due to shockinduced ventricular fibrillation, asystole and respiratory failure secondary to respiratory impairment, or paralysis of respiratory muscles. ${ }^{2}$ In the case of low tension with a frequency of 50-60 Hz, the current may cause convulsive contraction leading to muscle tetany and may also induce ventricular fibrillation. ${ }^{3}$ In many cases, electrical injuries to the hands produce devastating injuries involving deeper structures of the hands such as tendons, joint capsules and bone, and thus these injuries often require flaps or amputation. As for therapy, electrical injuries cause an increased frequency of acute and chronic abnormalities that need multidisciplinary approaches to therapy. ${ }^{4}$

To restore the protective sensation and flexion of fingers and thumb, multistage procedures are usually warranted according to different pathologic states of the injury. ${ }^{5}$ 
However, restoration of the function of the injured hands is an arduous, complicated process with modest improvement. The challenge for the reconstructive surgeon is to find simpler and better ways to restore protective sensation and digital flexion for patients who have suffered severe electrical injuries to their hands. There are many ways to restore the injured fingers, such as wrap-around flap, ${ }^{4}$ dorsalis pedis compound flap, ${ }^{6}$ super-thin abdominal skin pedicle flap, ${ }^{7}$ and neurovascularized instep free flap. ${ }^{8}$ However, each of these approaches has limitations and disadvantages, and more effective approaches are needed for restoring the injured fingers.

The purpose of this study was to introduce our clinical experiences of a one-stage restoration of using the lateral tarsal artery (LTA) flap to have successfully restore fingers after electrical burn. From 2005 to 2012, 10 patients with severe electrical burns to 14 fingers, including six thumbs and four index and four middle fingers, were satisfactorily reconstructed with this flap, and all flaps survived.

\section{Patients and methods}

\section{Clinical data}

From 2005 to 2012, 10 patients (seven males and three females, age ranged from 11 years to 50 years) were admitted by the Department of Burns and Plastic Surgery, Xiangya Hospital, Central South University. All the patients suffered severe electrical burns to their fingers, including six thumbs and four index and four middle fingers. These patients were recruited for this study. The protocols of this study were approved by the institutional ethics committee of Xiangya Hospital, Central South University, and written informed consents have been provided by the three patients to have their case details and accompanying images published. This study was conducted by following the principles of the Declaration of Helsinki.

The patients were treated with the LTA flaps. The wound size ranged from $2.0 \times 3.0 \mathrm{~cm}$ to $3.5 \times 5.0 \mathrm{~cm}$. The flap with free tendon graft was used to repair the tendon defect in four cases, free nerve graft was used to repair the feeling defect in two cases, and the flap with nerve was used to repair the feeling defect in two cases. All the patients were followed up for 3 months to 2 years.

\section{Surgical anatomy}

The LTA flap is an artery flap based on septocutaneous or musculocutaneous perforators supplied by the LTA. It arises from the dorsal pedal artery, such that the vessel crosses the navicular bone; it passes in an arched direction lateralward, lying upon the tarsal bones, and is covered by the extensor digitorum brevis. It supplies this muscle and the articulations of the tarsus and anastomoses with branches of the arcuate, anterior lateral malleolar and lateral plantar arteries and with the perforating branch of the peroneal artery. Along its course in the intermuscular septum, the LTA gives multiple cutaneous and muscular branches. The septocutaneous branches arise vertically and feed the rich arborizing and interconnected plexus under the skin of lateral dorsal aspect of foot. ${ }^{9}$

The diameter of the beginning of LTA ranges from $1.02 \mathrm{~mm}$ to $1.44 \mathrm{~mm}$, and the diameter of the proper palmar digital artery ranges from proxima interphalangeal joints plane (Figure 1). ${ }^{6}$

\section{Operative technique}

All cases were operated on as described subsequently. The operation was performed under tourniquet control and loop magnification with the aid of general anesthesia. After removing the necrotic tissue of the wound, a tissue defect with or without nerve or tendon defect was exposed. Then, the proximal of the involved side of the inherent digital artery and the dorsal digital vein or palmar digital vein were separated under microscope. The distribution of these vessels was marked, and the artery was in company with the vein. The tissue defect was template, and the edge was expanded $3 \mathrm{~mm}$ more. An appropriate flap was mapped out on the skin territory of the LTA flap. The design of the flap was in the shape of a spindle.

\section{Flap harvest and transplant}

The patency of the dorsalis pedis artery and LTA was confirmed preoperatively with Doppler ultrasonography.

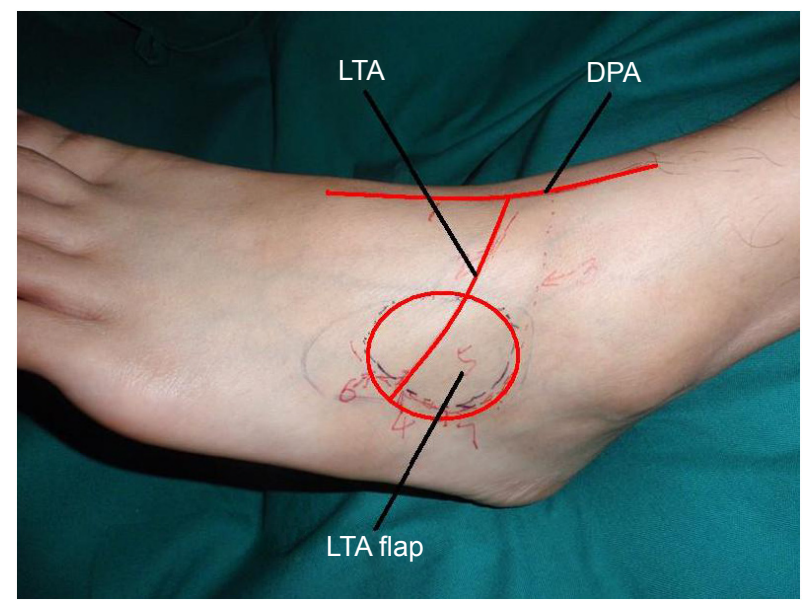

Figure I The anatomy of LTA and LTA flap. Abbreviations: DPA, dorsal pedal artery; LTA, lateral tarsal artery. 
The LTA axis of the LTA flap arose from the dorsalis pedis artery at the level of talonavicular articulation. A line drawn from the middle point of talonavicular articulation level to the basilar part of the fifth metatarsal bone was regarded as the projected surface of LTA.

A straight incision was made at the middle point of talonavicular articulation level, and the dorsalis pedis artery was located between the extensor hallucis longus tendon and extensor digitorum longus tendon. Abscission to the extensor digitorum brevis was avoided, and the LTA was exposed along the fibula side of dorsalis pedal artery. The LTA vena comitantes and lateral dorsal cutaneous nerve of foot were carefully protected during the dissection until they were perforated into the cutaneous. The flap was raised at the subfascial level and sutured around to prevent the fascia and skin from separating during the course of dissection. After the flap was totally elevated, the donor site was covered with a full skin graft from the abdomen. The free flap was transplanted to the defect area by anastomosing LTA with the proximal inherent digital artery; the LTA's venae comitantes were anastomosed with the involved side of dorsal digital vein or palmar digital vein.

\section{Results}

All skin flaps adhered successfully. The largest skin flap was $3.5 \times 5.0 \mathrm{~cm}$. All wounds were healed within 3 weeks. The follow-up period ranged from 3 months to 2 years. All the flaps showed good appearance and normal skin color with soft texture, and the sensibility of 2-point resolution ranged from $8 \mathrm{~mm}$ to $10 \mathrm{~mm}$. The transplanted tendons were functioning well. The flexion distance from tip to palmar crease and the extended distance from tip to the horizontal level were 4-5 cm and 3-4 cm, respectively. Patients and their relatives were pleased with the functional and esthetic outcomes.

\section{Case I}

A 40-year-old man suffered electrical injury to his left index finger. A deep third degree burn was observed. The movement of all fingers was normal, but the continuity of sensibility of index finger was not detected. The cutaneous defect of the left index finger was created with tendon exposed, nerve injured and radial inherent digital artery embolized after debridement. The free flap transplantation to restore the finger was offered in such situation. An LTA free flap measuring $3.0 \times 4.0 \mathrm{~cm}$ was transplanted from the right foot to the defect. The pedicle was anastomosed endto-end to the proximal radial inherent digital artery and the cutaneous vein at the dorsal digital vein, and the lateral dorsal cutaneous nerve of foot was anastomosed to the dorsal branch of radial nerve. The donor site was covered with a skin graft. The flap survived completely (Figure 2).

\section{Case 2}

A 37-year-old man suffered electrical injury to his right thumb. The thumb wound was treated with skin graft at the beginning. However, this treatment resulted in skin grafts necrosis, and thus, the thumb wound was unhealed. After debridement of the thumb, the cutaneous defect of thumb was created with tendon and the interphalangeal joint cavity of the thumb was exposed. The free flap transplantation was offered to restore the thumb in such situation. An LTA free flap measuring $3.0 \times 3.0 \mathrm{~cm}$ was transplanted from the left foot to the defect. The pedicle was anastomosed end-to-end to the proximal ulnar inherent digital artery and the cutaneous vein at the dorsal digital vein. The donor site was covered with a skin graft. The flap survived completely (Figure 3).

\section{Case 3}

A 35-year-old man suffered electrical injury in his right thumb and palm. The cutaneous defect of thumb was created with tendon and the interphalangeal joint cavity of thumb exposed after debridement. The free flap transplantation was offered to restore the finger and skin graft to palm in such situation. A LTA free flap measuring $3.0 \times 5.0 \mathrm{~cm}$ was transplanted from the left foot to the defect. The pedicle was anastomosed end-to-end to the proximal radial inherent digital artery and the cutaneous vein at the digital palmar vein. The donor site was covered with a skin graft. The flap survived completely (Figure 4).

\section{Discussion}

Among severe burns, the more frequent burns are hand injuries. In contrast to burns caused by flame or scald, electrical burns are more frequently located to the upper extremity only; the incidence rate is even as high as $58 \%$. High and low voltage contact often causes devastating injuries, frequently with the involvement of deeper structures such as tendons and bones, ${ }^{1,10}$ and an immediate escharotomy and fasciotomy are always offered. ${ }^{11}$ Some electrical burn injuries resemble a crush syndrome. ${ }^{12,13}$ The damage to the tissues is three dimensional with the current, producing extensive necrosis in the tissues at different levels from skin to bone, and amputation could be unavoidable. However, after debridement and primary cover, the distal blood supply and continuity of sensibility of some electrically burnt fingers still exists. In case of an unclear situation (after debridement), 

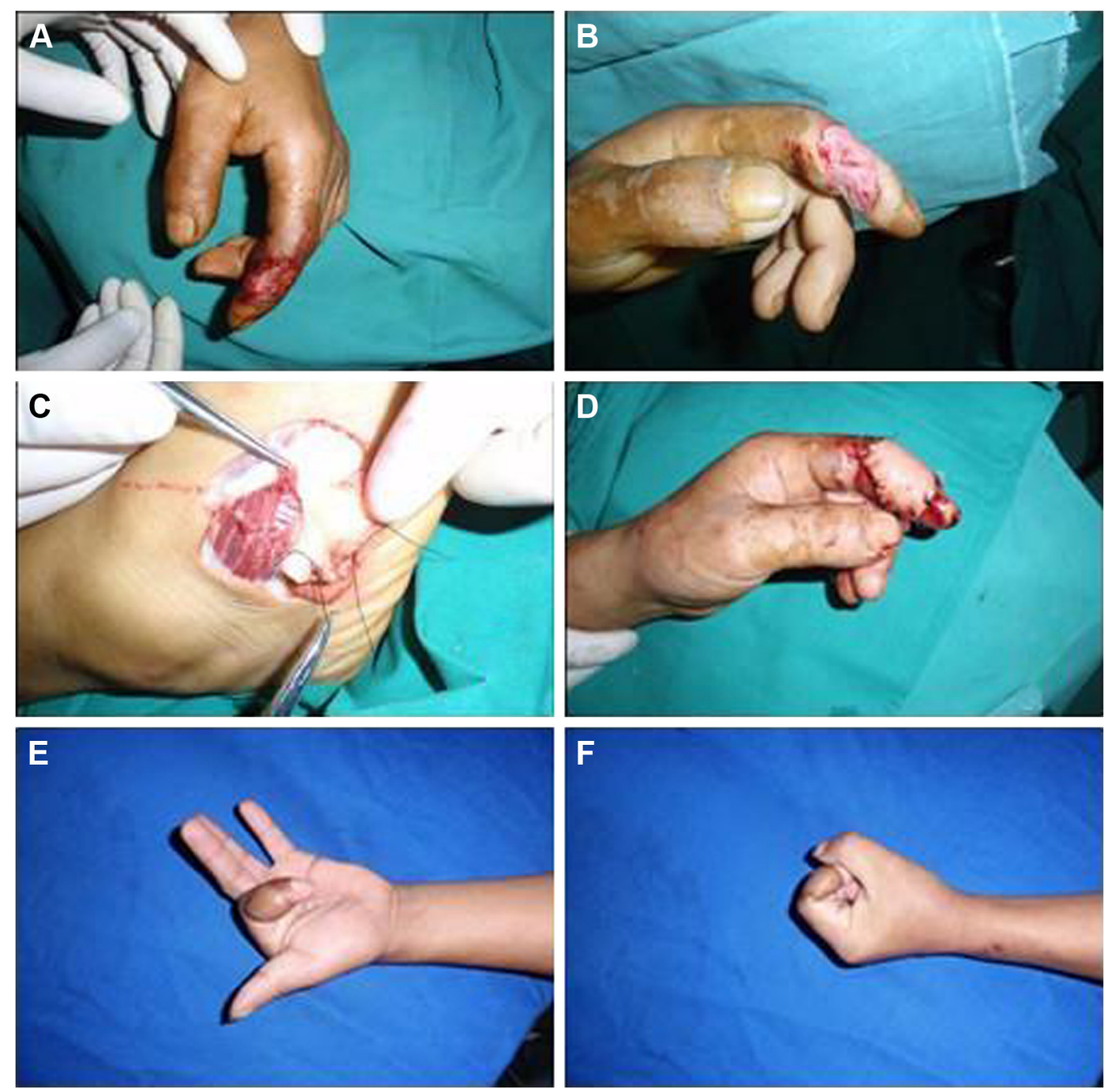

Figure 2 Electrical injury to the left index finger treated with the free LTA flap (Case I).

Notes: (A) The patient's left index finger after being injured electrically. (B) The cutaneous loss with tendon exposed, nerve injured and radial inherent artery embolized. (C) The LTA flap harvest. (D) The immediate postoperative appearance. (E-F) The physical appearance and functional outcome of the left hand 2 months after surgery. Abbreviation: LTA, lateral tarsal artery.

we would recommend a second look $24 \mathrm{~h}$ later to ensure that the remaining tissue is viable and not infected. ${ }^{11}$ In such situation, instituting a primary cover with free flap should be followed. Otherwise, there could be a high risk of secondary damage due to infection.

For reconstruction of the injured hands, the ideal flap should have the following features: like tissue for replacing like area, thin and pliable flap for remolding the hand contour, minimal morbidity at the donor site and sizable pedicle for microsurgical anastomosis. Additionally, change of intraoperative position should not be necessary. ${ }^{14}$

Several types of flaps have been used in coverage of finger defects, including abdominal flap, cross-arm flaps, pedicled antebrachial flap and even free flap graft. Two-stage procedures such as abdominal flaps and cross-arm flaps require
2-3 weeks of immobilization and are often bulky and require subsequent revision. ${ }^{15,16}$ The pedicled antebrachial flap has been criticized because of the sacrifice of a major artery to the hand and the poor donor-site result. ${ }^{17,18}$ These problems can be partially resolved by the retrograding radial fascia-fat forearm flap, which removes only the fascia and fat layers of the forearm tissue and leaves the radial artery and the forearm skin intact. ${ }^{19}$ However, there are some disadvantages of this flap. For instance, the adipofascial pedicle is relatively bulky after rotation, which makes direct closure dangerous to the pedicle, and it is difficult to extend to the distal hand. ${ }^{20} \mathrm{With}$ the progress of microsurgery, the applications of free flaps have become increasingly popular. Among these free flaps, the lateral arm flap is limited by its short pedicle; the scapular flap requires a change of position during the operation, 

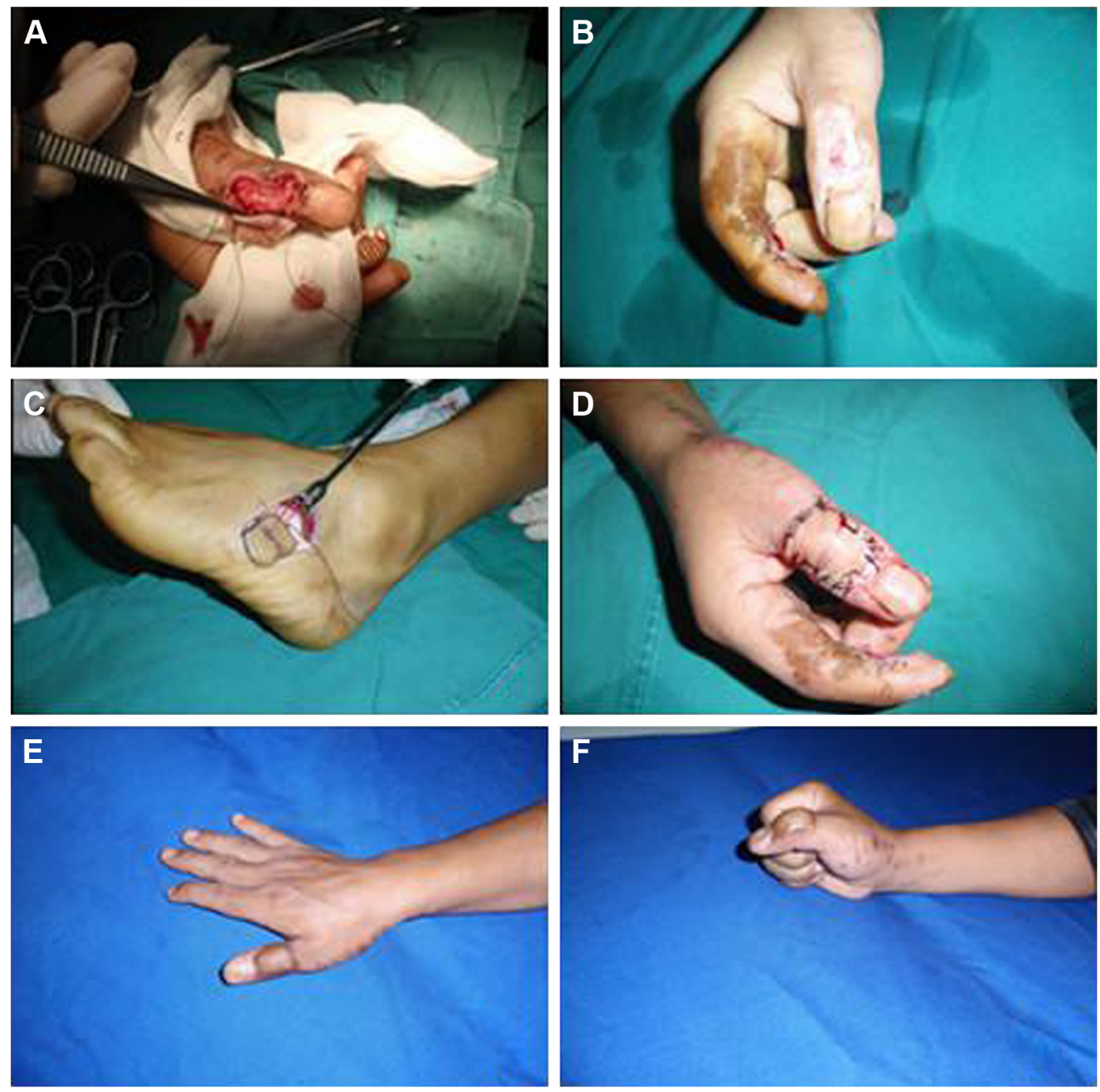

Figure 3 Electrical injury to the right thumb treated with the free LTA flap (Case 2).

Notes: (A) The right thumb after an electrical injury and the failed skin graft. (B) The cutaneous loss with tendon and the interphalangeal joint cavity of the thumb exposed. (C) The LTA flap harvest. (D) The immediate postoperative appearance. (E-F) The physical appearance and functional outcome of the right hand at 2 months after surgery.

Abbreviation: LTA, lateral tarsal artery.

hindering a two-team approach; the anterolateral thigh flap has become the standard flap for soft-tissue defects, but it is bulky when it is applied in the hands, and the toe web flap has the similar texture to hand, but its application is limited by its size. ${ }^{21,22}$ Dorsalis pedis or medial plantar free flaps would sacrifice a major vessel. ${ }^{23,24}$

Based on our clinical experience, we believe that the LTA flap is suitable for restoring fingers after electrical burns. Anatomical research in the literature has demonstrated that the external diameter of the LTA is $1.42 \pm 0.34 \mathrm{~mm}$, length is $6.2 \pm 1.1 \mathrm{~cm}$ and patency is $100 \% .^{25,26}$ The advantages of LTA are obvious because it includes suitable vessel diameter, similar color and texture to those of hand and acceptable morbidity at the donor site. ${ }^{27-29}$ In our cases of patients, the satisfactory results of treatment with LTA flap have confirmed the anatomic basis of the LTA flap for its application as a free flap, which can be devised according to the different repair regions to restore the defected soft tissues of the hand.

In addition, the nerve and tendon defects often happened in electrical injuries to fingers. The LTA flap can easily get the nerve from lateral dorsal cutaneous nerve of foot and tendon to graft; thus, it is a simpler and better way to restore the protective sensation and digital flexion for patients who have suffered severe injuries to their fingers.

However, a basic microsurgery technique is necessary in using this method, and the skin graft on the foot is prone to hypertrophic scarring caused by friction of the skin graft 

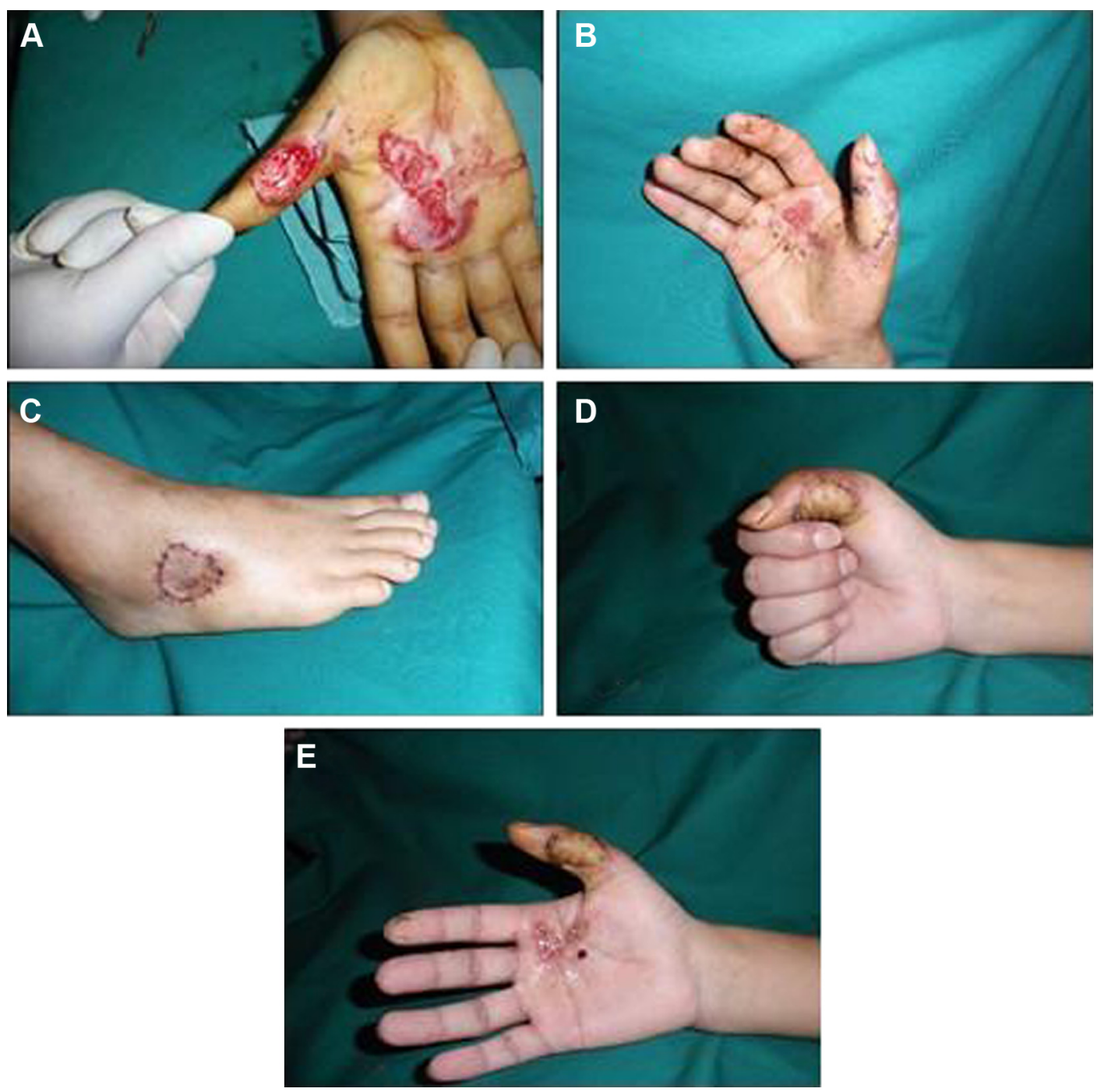

Figure 4 Electrical injury to the right thumb treated with the free LTA flap (Case 3).

Notes: (A) The right thumb and palm after electrical injury and the cutaneous loss with tendon and the thumb's interphalangeal joint cavity exposed. (B) The physical appearance 2 weeks after surgery. (C) Donor site 2 weeks after surgery. (D-E) The physical appearance and functional outcome of the right hand at 2 months after surgery.

against footwear when patients are walking. Patients must be informed of this problem before surgery.

Additionally, considering that there are only two LTA flaps in each patient and that the value of a functioning finger like thumb is immense, the LTA flap would be better to restore the function fingers.

\section{Conclusion}

In summary, LTA flap is a reliable method to restore fingers after severe electrical injuries. The LTA flap provides a thin, pliable, vascularized tissue for reconstruction of fingers due to the injuries caused by electrical burns.

\section{Acknowledgments}

This study was supported by the Science and Technology Department of Hunan Province grants. No part of this manuscript has been published previously or concurrently submitted for publication elsewhere. All the authors have read and approved the final version of this manuscript.

\section{Disclosure}

The authors report no conflicts of interest in this work.

\section{References}

1. Sheridan RL, Hurley J, Smith MA, et al. The acutely burned hand: management and outcome based on a ten-year experience with 1047 acute hand burns. $J$ Trauma. 1995;38(3):406-411.

2. Hsueh YY, Chen CL, Pan SC. Analysis of factors influencing limb amputation in high-voltage electrically injured patients. Burns. 2011; 37(4):673-677.

3. El MS, Fejjal N, Hafidi J, et al. [Skin grafting in the treatment of hand burns sequelae in relation to 152 cases. Report from Department of Plastic Surgery, University Hospital Ibn Sina]. Ann Burns Fire Disasters. 2010;23(1):39-42. 
4. Kempny T, Lipový B, Hokynková A, Lorenz L, Klosová H. Wraparound flap in urgent thumb reconstruction after high-voltage electrical injury. Burns. 2012;38(7):e20-e23.

5. Lee RC. Injury by electrical forces: pathophysiology, manifestations, and therapy. Curr Probl Surg. 1997;34(9):677-764.

6. Eo S, Kim Y, Kim JY, Oh S. The versatility of the dorsalis pedis compound free flap in hand reconstruction. Ann Plast Surg. 2008;61(2): 157-163.

7. Gousheh J, Arasteh E, Mafi P. Super-thin abdominal skin pedicle flap for the reconstruction of hypertrophic and contracted dorsal hand burn scars. Burns. 2008;34(3):400-405.

8. Oh SJ, Koh SH, Chung CH. Wide thumb and the first web reconstruction using a neurovascularised instep free flap. J Plast Reconstr Aesthet Surg. 2010;63(9):1565-1568.

9. Huang D, Wang HG, Zhao CY, Wu WZ. An alternative approach in the treatment of thumb web contracture skin defects: lateral tarsal artery flap. Chin Med J (Engl). 2009;122(18):2133-2137.

10. Harvey KD, Barillo DJ, Hobbs CL, et al. Computer-assisted evaluation of hand and arm function after thermal injury. J Burn Care Rehabil. 1996;17(2):176-180; discussion 175.

11. Windhofer C, Gruber S, Hofer E, Papp C. Free flap survival despite severe anemia after fourth degree hand burn. Burns. 2006;32(2):261-265.

12. Artz CP. Changing concepts of electrical injury. Am J Surg. 1974; 128(5):600-602.

13. Adam AL, Klein M. Electrical cataract notes on a case and a review of the literature. Br J Ophthalmol. 1945;29(4):169-175.

14. Adani R, Tarallo L, Marcoccio I, Cipriani R, Gelati C, Innocenti M. Hand reconstruction using the thin anterolateral thigh flap. Plast Reconstr Surg. 2005;116(2):467-473; discussion 474-477.

15. Miura T. Use of paired abdominal flaps for release of adduction contractures of the thumb. Plast Reconstr Surg. 1979;63(2):242-244.

16. Bonola A, Fiocchi R. Cross-arm double flap in the repair of severe adduction contracture of the thumb. Hand. 1975;7(3):287-290

17. Chen HC, el-Gammal TA. The lateral arm fascial free flap for resurfacing of the hand and fingers. Plast Reconstr Surg. 1997;99(2):454-459.
18. Hsieh CH, Yang CC, Kuo YR, Tsai HH, Jeng SF. Free anterolateral thigh adipofascial perforator flap. Plast Reconstr Surg. 2003;112(4): 976-982.

19. Weinzweig N, Chen L, Chen ZW. The distally based radial forearm fasciosubcutaneous flap with preservation of the radial artery: an anatomic and clinical approach. Plast Reconstr Surg. 1994;94(5): 675-684.

20. Chang SM, Hou CL, Zhang F, Lineaweaver WC, Chen ZW, Gu YD. Distally based radial forearm flap with preservation of the radial artery: anatomic, experimental, and clinical studies. Microsurgery. 2003 ; 23(4):328-337.

21. Kuo YR, Seng-Feng J, Kuo FM, Liu YT, Lai PW. Versatility of the free anterolateral thigh flap for reconstruction of soft-tissue defects: review of 140 cases. Ann Plast Surg. 2002;48(2):161-166.

22. Dabernig J, Shelley OP, Schaff J. The innervated free toe web flap for clitoris reconstruction. J Plast Reconstr Aesthet Surg. 2007;60(12): 1352-1355.

23. Ritz M, Mahendru S, Somia N, Pacifico MD. The dorsalis pedis fascial flap. J Reconstr Microsurg. 2009;25(5):313-317.

24. Duman H, Er E, Işík S, et al. Versatility of the medial plantar flap: our clinical experience. Plast Reconstr Surg. 2002;109(3):1007-1012.

25. Sham E, Choi WT, Flood SJ. Lateral supramalleolar flap in reconstruction of pressure ulcers in patients with spinal cord injury. ANZ J Surg. 2008;78(3):167-171.

26. Touam C, Rostoucher P, Bhatia A, Oberlin C. Comparative study of two series of distally based fasciocutaneous flaps for coverage of the lower one-fourth of the leg, the ankle, and the foot. Plast Reconstr Surg. 2001; 107(2):383-392.

27. Lee JH, Dauber W. Anatomic study of the dorsalis pedis-first dorsal metatarsal artery. Ann Plast Surg. 1997;38(1):50-55.

28. Hashimoto I, Yoshinaga R, Toda M, Nakanishi H. Intractable malleolar bursitis treated with lateral calcaneal artery adipofascial flap. Br J Plast Surg. 2003;56(7):701-703.

29. Borrelli JJ, Lashgari C. Vascularity of the lateral calcaneal flap: a cadaveric injection study. J Orthop Trauma. 1999;13(2):73-77.
Therapeutics and Clinical Risk Management

\section{Publish your work in this journal}

Therapeutics and Clinical Risk Management is an international, peerreviewed journal of clinical therapeutics and risk management, focusing on concise rapid reporting of clinical studies in all therapeutic areas, outcomes, safety, and programs for the effective, safe, and sustained use of medicines. This journal is indexed on PubMed Central, CAS,

\section{Dovepress}

EMBase, Scopus and the Elsevier Bibliographic databases. The manuscript management system is completely online and includes a very quick and fair peer-review system, which is all easy to use. Visit http://www.dovepress.com/testimonials.php to read real quotes from published authors. 